\title{
Tribromomelamine: A Novel and Efficient Catalyst for the Synthesis 2-Arylthiazolines under Solvent-free
} Conditions

\author{
LIQIANG WU
}

School of Pharmacy, Xinxiang Medical University, Xinxiang, Henan 453003, P. R. China

Email:wliq870@163.com

Received 20 July 2011; Accepted 5 September 2011

\begin{abstract}
A novel procedure for the synthesis of 2-arylthiazolines through one-pot condensation of of nitriles with 2-aminoethanethiol in the presence of tribromomelamine as catalyst under solvent-free conditions is described.
\end{abstract}

Keywords: 2-Arylthiazolines, 2-Aminoethanethiol, Nitriles, Tribromomelamine, Synthesis

\section{Introduction}

Natural compounds possessing thiazoline moiety have been attracted by their antibiotic ${ }^{1}$, antitumor $^{2}$, antimalarial ${ }^{3}$, antiproliferative ${ }^{4}$, anti-HIV activities ${ }^{5}$. A plethora of biological activities have also been associated with a large number of synthetic thiazoline analogs ${ }^{6}$.

In the last decade organocatalysis has became a field of great interest ${ }^{7}$. Organocatalysts are usually robust, inexpensive, readily available, non-toxic and inert towards moisture and oxygen. Because of the absence of transition metals, organocatalytic methods seem to be especially attractive for the preparation of compounds that do not tolerate metal contamination such as pharmaceutical products.

In this article, we wish to report a metal-free synthesis of 2-arylthiazolines using a new, efficient and easily prepared reagent, tribromomelamine (TBM) (Scheme 1). 


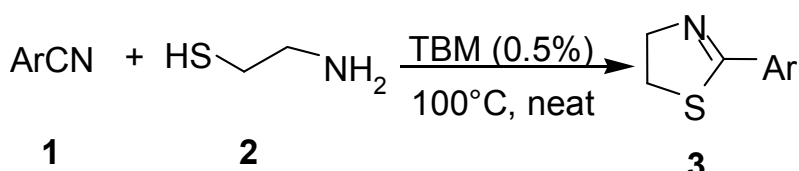

Scheme 1

TBM is readily prepared by the dropwise addition of $\mathrm{Br}_{2}$ to $5 \mathrm{M} \mathrm{NaOH}$ mixture of melamine at at room temperature ${ }^{8}$. It is interesting to note that the producing of TBM is easy and clean without a difficult work-up procedure. This yellow homogeneous, nonhygroscopic solid is very stable under reaction conditions.(Scheme 2).<smiles>Nc1nc(N)nc(N)n1</smiles>

TBM

Scheme 2

\section{Experimental}

NMR spectra were recorded on Bruker AV-400 spectrometer at room temperature using TMS as an internal standard, coupling constants $(J)$ were measured in $\mathrm{Hz}$; Elemental analysis were performed by a Vario-III elemental analyzer; Melting points were determined on a XT-4 binocular microscope and were uncorrected; TBM was prepared by available method $^{8}$; Commercially available reagents were used throughout without further purification unless otherwise stated.

General Procedure for synthesis of 3

A mixture of the nitrile ( $1 \mathrm{mmol}), 2$-aminoethanethiol $(1 \mathrm{mmol})$, and TBM $(0.005 \mathrm{mmol})$ was stirred at $100{ }^{\circ} \mathrm{C}$ for the appropriate time according to Table 3.Completion of the reaction was indicated by TLC. The reaction was cooled to room temperature, and the crude product purified by silica gel column chromatography using n-hex-ane/EtOAc $(v: v=2: 1)$ as eluent to afford the pure product. 
Spectral data of new 2-arylbenzothiazole

2-(3-Florophenyl)thiazoline (3h). IR ( $\mathrm{KBr}) v$ : $1600(\mathrm{CN}) ;{ }^{1} \mathrm{H} \mathrm{NMR}\left(\mathrm{CDCl}_{3}, 400 \mathrm{MHz}\right)$ $\delta: 7.68$ (s, 1H, Ar), 7.53 (d, 1H, $J=7.6 \mathrm{~Hz}, \mathrm{Ar}), 7.38$ (d, 1H, $J=7.6 \mathrm{~Hz}$. Ar), 7.22 (t, 1H, $J=$ $7.6 \mathrm{~Hz}, \mathrm{Ar}), 4.20\left(\mathrm{t}, J=8.0 \mathrm{~Hz}, 2 \mathrm{H}, \mathrm{CH}_{2} \mathrm{~N}\right), 3.32$ (t, $\left.J=8.0 \mathrm{~Hz}, 2 \mathrm{H}, \mathrm{CH}_{2} \mathrm{~S}\right)$ ); Anal. calcd for $\mathrm{C}_{9} \mathrm{H}_{8} \mathrm{FNS}$ : C 59.65, H 4.45, N 7.73, S 17.69\%; found: C 60.01, H 4.39, N 7.70, S 17.55\%.

\section{Results and Discussion}

In order to optimize the reaction conditions, first, the effect of temperature on the rate of the reaction was studied for the preparation of 2-phenylthiazoline in presence of $0.5 \mathrm{~mol} \%$ TBM under solvent-free conditions (Table 1). At $100{ }^{\circ} \mathrm{C}$, the reaction proceeded smoothly and gave short reaction time and high yield. Therefore, we kept the reaction temperature at $100{ }^{\circ} \mathrm{C}$.

Table 1. Temperature optimization for the synthesis of synthesis of 2-phenylthiazoline ${ }^{\mathrm{a}}$.

\begin{tabular}{cccc}
\hline Entry & Temperature $/{ }^{\circ} \mathrm{C}$ & Time $/ \mathrm{min}$ & Yield $/ \%{ }^{\mathrm{b}}$ \\
\hline 1 & 25 & 120 & 0 \\
2 & 50 & 90 & 0 \\
3 & 60 & 60 & 18 \\
4 & 70 & 30 & 30 \\
5 & 80 & 30 & 52 \\
6 & 90 & 10 & 78 \\
7 & 100 & 3 & 98 \\
8 & 110 & 3 & 98 \\
9 & 120 & 2 & 96 \\
10 & 130 & 2 & 97 \\
\hline
\end{tabular}

\footnotetext{
${ }^{\mathrm{a}}$ Reaction conditions: benzonitrile $(1 \mathrm{mmol})$; 2-aminoethanethiol $(1 \mathrm{mmol})$; TBM (0.005 mmol); neat.

${ }^{\mathrm{b}}$ Isolated yield.
}

Next, the study set out to determine optimal amount of TBM, the reaction was carried out by varying amount of the catalyst (Table 2). Maximum yield was obtained with 0.5 
mol\% of the catalyst. Further increase in amount of alum in the mentioned reaction did not has any significant effect on the product yield.

Table 2. The amounts of catalyst optimization for the synthesis of 2-phenylthiazoline ${ }^{\mathrm{a}}$.

\begin{tabular}{|c|c|c|c|}
\hline Entry & $\mathrm{TBM} / \mathrm{mol} \%$ & Time/ min & Yield $/ \%{ }^{b}$ \\
\hline 1 & 0 & 60 & 0 \\
\hline 2 & 0.1 & 10 & 72 \\
\hline 3 & 0.2 & 4 & 81 \\
\hline 4 & 0.3 & 4 & 89 \\
\hline 5 & 0.4 & 3 & 95 \\
\hline 6 & 0.5 & 3 & 98 \\
\hline 7 & 0.6 & 3 & 98 \\
\hline 8 & 0.7 & 3 & 97 \\
\hline 9 & 0.8 & 2 & 96 \\
\hline 10 & 0.9 & 2 & 98 \\
\hline 11 & 1 & 2 & 98 \\
\hline
\end{tabular}

${ }^{\text {a }}$ Reaction conditions: benzonitrile $(1 \mathrm{mmol}) ; 2$-aminoethanethiol $(1 \mathrm{mmol}) ; 100{ }^{\circ} \mathrm{C}$; neat.

${ }^{\mathrm{b}}$ Isolated yield.

In order to extend the above reaction to a library system, various kinds of arylnitriles (Table 3) were subjected to react with 2-aminoethanethiol to give the corresponding 2-arylthiazolines, and representative examples are shown in Table 3. All of arylnitriles gave expected products at high yields, either bearing electron-withdrawing groups (such as halide, nitro) or electron-donating groups (such as alkyl group) under the same reaction condition. To further demonstrate the scope and limitation of the substrates, aliphatic nitriles, such as pentanenitrile, heptanenitrile, were used as reactants to react with 2-aminoethanethiol. However, the desired products were not found and obtained successfully. All of the structures were characterized by IR, ${ }^{1} \mathrm{H}$ NMR and elemental analysis. 
Table 3. Preparation of 2-arylthiazolines ${ }^{\mathrm{a}}$.

\begin{tabular}{|c|c|c|c|c|c|}
\hline$\overline{\text { Entry }}$ & $\mathrm{Ar}$ & Time/ min & Products $^{b}$ & Yield $/ \%^{b}$ & m.p. (lit.) $/{ }^{\circ} \mathrm{C}$ \\
\hline 1 & $\mathrm{C}_{6} \mathrm{H}_{5}$ & 3 & $3 \mathbf{a}$ & 98 & $127-129(126-128)^{6 i}$ \\
\hline 2 & $4-\mathrm{Cl}-\mathrm{C}_{6} \mathrm{H}_{4}$ & 2 & $\mathbf{3 b}$ & 96 & $51-53(53-55)^{6 n}$ \\
\hline 3 & $4-\mathrm{Me}-\mathrm{C}_{6} \mathrm{H}_{4}$ & 6 & $3 c$ & 82 & $40-41(39-41)^{6 n}$ \\
\hline 4 & $4-\mathrm{MeO}-\mathrm{C}_{6} \mathrm{H}_{4}$ & 6 & 3d & 81 & $55-56(53-55)^{6 \mathrm{i}}$ \\
\hline 5 & $4-\mathrm{NO}_{2}-\mathrm{C}_{6} \mathrm{H}_{4}$ & 2 & $3 e$ & 88 & $147-149(148-150)^{6 n}$ \\
\hline 6 & $4-\mathrm{F}-\mathrm{C}_{6} \mathrm{H}_{4}$ & 3 & $3 f$ & 92 & oil (oil) $)^{6 n}$ \\
\hline 7 & $3-\mathrm{NO}_{2}-\mathrm{C}_{6} \mathrm{H}_{4}$ & 5 & $3 g$ & 87 & $133-134(135-137)^{6 i}$ \\
\hline 8 & $3-\mathrm{F}-\mathrm{C}_{6} \mathrm{H}_{4}$ & 5 & $3 \mathrm{~h}$ & 93 & oil \\
\hline 9 & 2-Cl- $\mathrm{C}_{6} \mathrm{H}_{4}$ & 4 & $3 \mathbf{i}$ & 99 & Oil (oil) $)^{6 n}$ \\
\hline 10 & 2-Pyridyl & 7 & $3 \mathbf{j}$ & 98 & $90-92(91-93)^{6 n}$ \\
\hline 11 & 3-Pyridyl & 5 & $3 k$ & 94 & $110-112(111-113)^{6 \mathrm{i}}$ \\
\hline 12 & 4-Pyridyl & 3 & 31 & 99 & $72-73(74-76)^{6 n}$ \\
\hline 13 & 2-Thienyl & 6 & $3 m$ & 90 & $39-40(40-42)^{6 i}$ \\
\hline
\end{tabular}

${ }^{\mathrm{a}}$ Reaction conditions: nitrile ( $\left.1 \mathrm{mmol}\right)$; 2-aminoethanethiol $(1 \mathrm{mmol})$; TBM $(0.005 \mathrm{mmol})$; $100{ }^{\circ} \mathrm{C}$; neat.

${ }^{\mathrm{b}}$ Isolated yield.

Since TBM contains bromine atoms attached to nitrogen atoms, it is likely that it releases $\mathrm{Br}^{+}$in situ, which acts as a catalyst in the reaction medium. Therefore, the mechanism shown in Scheme 3 can be suggested for this conversion.

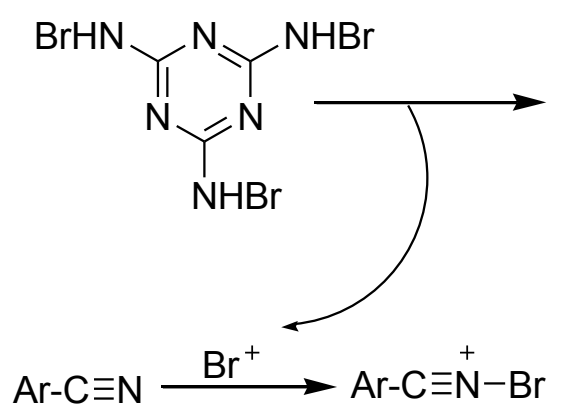<smiles>[NH-]c1nc([NH-])nc([NH-])n1</smiles>

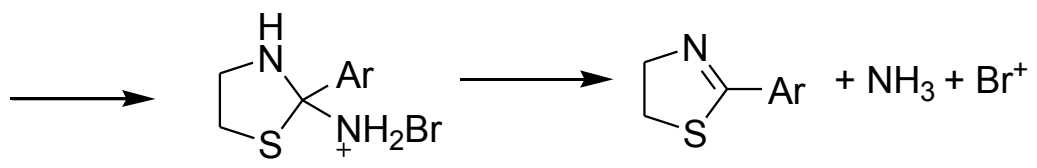

Scheme 3 


\section{Conclusion}

In conclusion, an efficient protocol for the one-pot preparation of 2-arylthiazolines from the condensation reaction of nitriles with 2-aminoethanethiol in the presence of TBM was described. The reactions were carried out under thermal solvent-free conditions with short reaction time and produced the corresponding products in good to excellent yields.

\section{Acknowledgments}

We are pleased to acknowledge the financial support from Xinxiang Medical University.

\section{References}

1. Aaron, M. S.; Richard, A. L.; David, C. R. J. Nat. Prod. 2007, 70, 1793.

2. (a) Yu, L.; Li, Z.; Peng, C.; Li, Z.; Guo, Y. Helv. Chim. Acta. 2009, 92, 607; (b) Matsuo, Y.; Kanoh, K.; Imagawa, H.; Adachi, K.; Nishizawa, M.; Shizuri, Y. J. Antib. 2007, 60, 256;

(c) Gerwick, W. H.; Proteau, P. J.; Nagle, D. G.; Hamel, E.; Blokhin, A.; Slate, D. J. Org. Chem. 1994, 59, 1243.

3. Linington, R. G.; Gonzalez, J.; Urena, L.; Romero, L. I.; Ortega-Barria, E.; Gerwick, W. H. J. Nat. Prod. 2007, 70, 397.

4. Teruya, T.; Sasaki, H.; Fukazawa, H.; Suenaga, K. Org. Lett. 2009, 11, 5062.

5. Perez. L. J.; Faulkner, D. J. J. Nat. Prod. 2003, 66, 247.

6. (a) Fu, B.; Qi, Q.-Q.; Lu, X.-H.; Cheng, X.-M.; Xiao, Y.-M.; Li, N. Chin. J. Org.Chem. 2008, 28, 1358; (b) Davyt, D.; Serra, G.; Mar. Drugs 2010, 8, 2755; (c) Sondhi, S. M.; Dwivedi, A. D.; Singh, J.; Gupta, P. P. Indian J. Chem., Sect B 2010, 49B, 1076; (d) Padmavathi, V.; Mahesh, K.; Reddy, G. Dinneswara; Padmaja, A. Eur. J. Med. Chem. 2010, 45, 3178; (e) Saeed, A.; Shaheen, U.; Hameed, A.; Kazmi, F. J. Fluorine Chem. 2010, 131, 333; (f) Sondhi, S. M.; Rani, R.; Gupta, P. P.; Agrawal, S. K.; Saxena, A. K. Mol. Divers. 2009, 13, 357; (g) Seijas, J. A.; Vazquez-Tato, M. P.; Crecente-Campo, J. Tetrahedron 2008, 64, 9280; (h) Singh, R. K.; Lange, T. S.; Kim, K. K.; Singh, A. P.; Hopson, R.; Vorsa, N.; Brard, L. Lett. Org. Chem. 2008, 5, 103; (i) Mohammadpoor-Baltork, I.; Moghadam, M.; Tangestaninejad, S.; Mirkhani, V.; Hojati, S. F. Catal. Commun. 2008, 9, 1153; (j) Mohammadpoor-Baltork, I.; Moghadam, M.; Tangestaninejad, S.; Mirkhani, V.; Hojati, S. F. Polyhedron 2008, 27, 750; (k) Fukuhara, T.; Hasegawa, C.; Hara, S. Synthesis 2007, 1528; (1) Sanemitsu, Y.; Kawamura, S.; Satoh, J.; Katayama, T.; Hashimoto, S. J. Pestic. Sci. 2006, 31, 305; (m) Bonde, C. G.; Gaikwad, N. J. Bioorg. Medi. Chem. 2004, 12, 2151; (n) Shaabani, A.; Seyyedhamzeh, M.; Maleki, A.; Rezazadeh, F. Appl. Catal. A 2009, 358, 146. 
7. (a) Dalko, P. I.; Moisan, L. Angew. Chem. Int. Ed. Engl. 2004, 43, 5138; (b) Duthaler, R. O. Angew. Chem. Int. Ed. Engl. 2003, 42, 975.

8. Ghorbani-Choghamarani, A.; Zolfigol, M. A.; Hajjami, M.; Jafari, S. J. Chin. Chem. Soc. 2008, 55, 1208. 


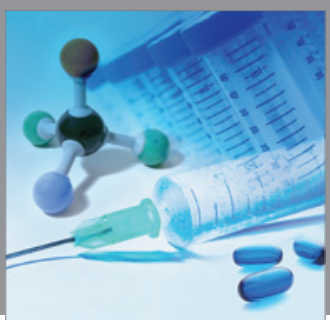

International Journal of

Medicinal Chemistry

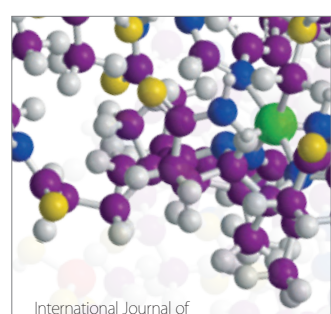

Carbohydrate Chemistry

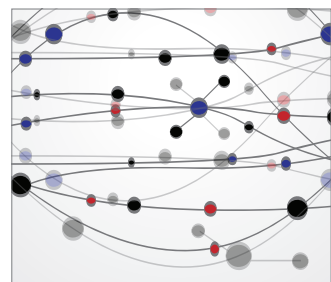

The Scientific World Journal
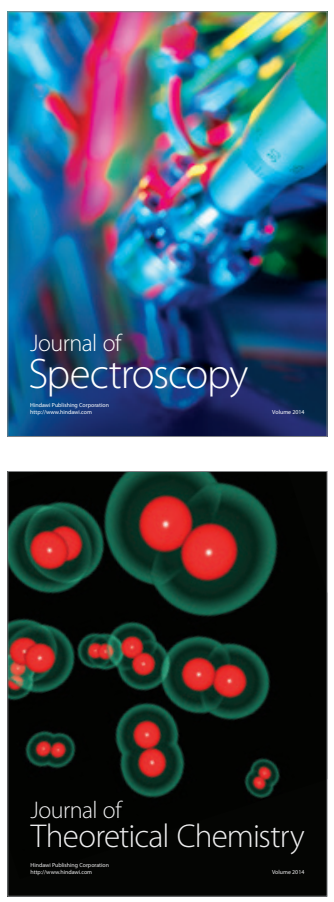
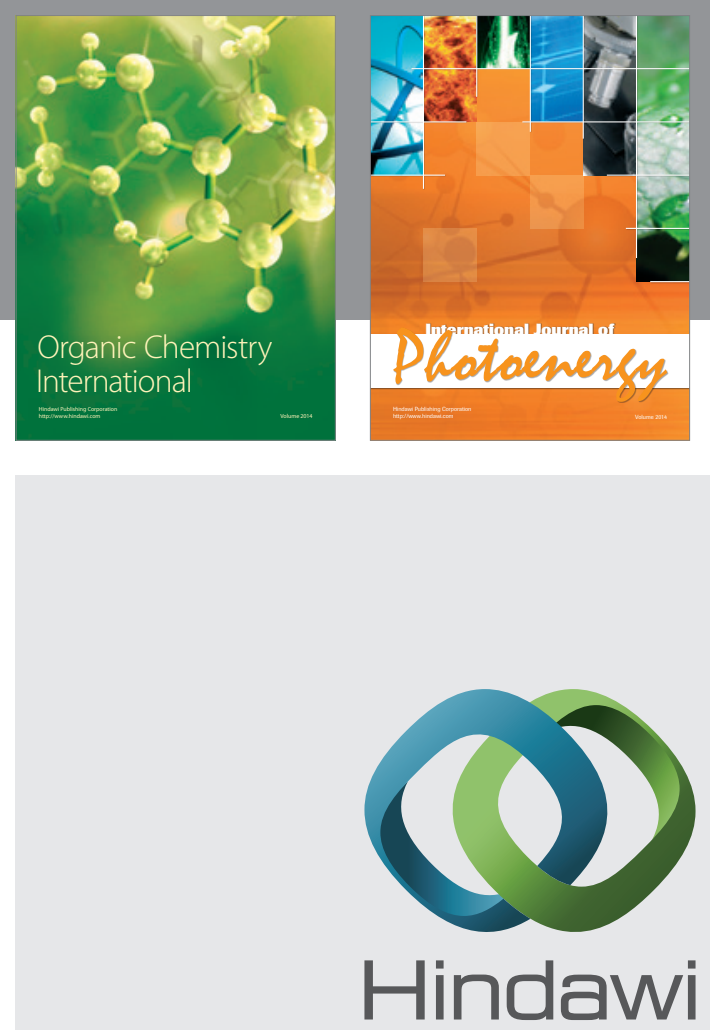

Submit your manuscripts at

http://www.hindawi.com
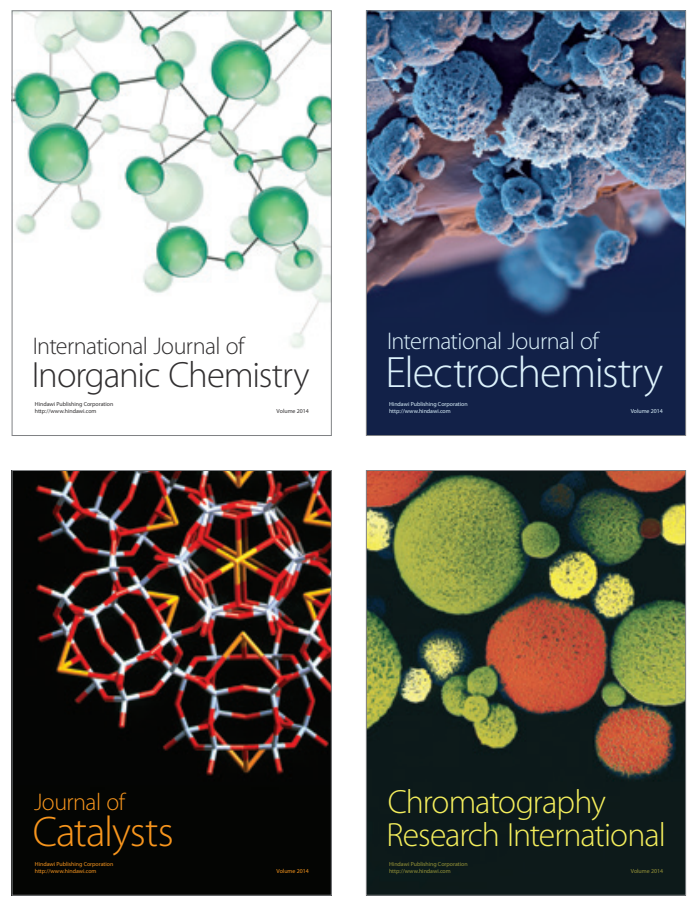
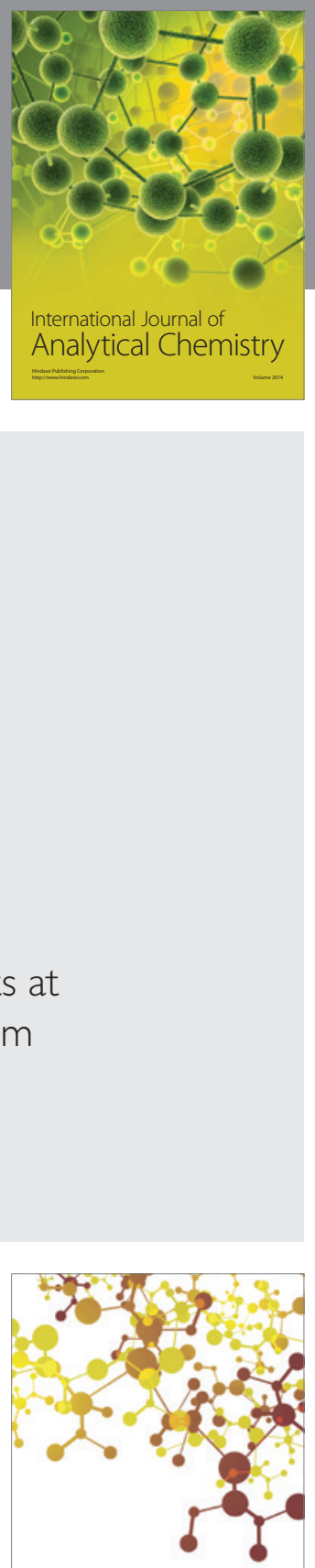

Journal of

Applied Chemistry
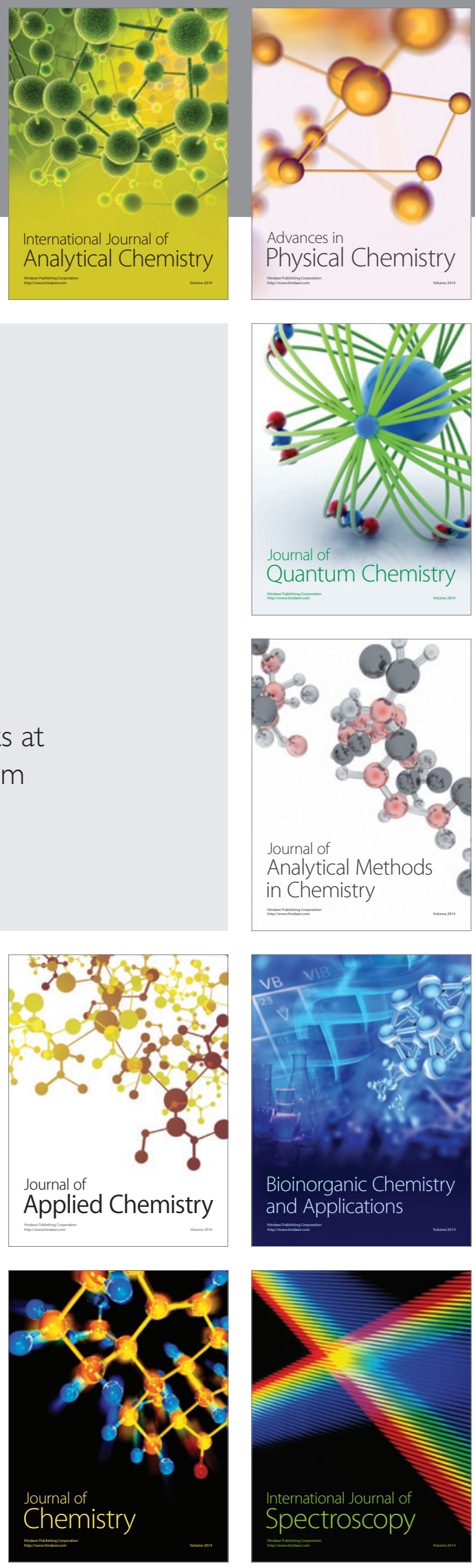